\title{
AVALIAÇÃO DA GERAÇÃO DE METANO POR DIFERENTES INÓCULOS UTILIZANDO GLICEROL E MELAÇO DE SOJA COMO SUBSTRATO
}

\author{
I. R. CITELLI ${ }^{1}$, A. SARTI ${ }^{1}$, S. I. MAINTINGUER ${ }^{2}$ L. O. PIRES ${ }^{1}$ \\ ${ }^{1}$ Universidade Estadual Paulista "Julio de Mesquita Filho", Instituto de Química, \\ Departamento de Bioquímica e Tecnologia Química \\ ${ }^{2}$ Universidade Estadual Paulista "Julio de Mesquita Filho", Instituto de Pesquisa em \\ Bioenergia \\ E-mail para contato: isacitelli_93@hotmail.com
}

\begin{abstract}
RESUMO - Processos anaeróbios podem ser empregados com o intuito de degradar resíduos de processos industriais e produzir o gás metano, que, como fonte de energia, possui um reduzido potencial poluidor quando comparado a combustíveis fósseis, sendo uma ótima alternativa como fonte renovável. Exemplos desses resíduos são o glicerol, subproduto da produção de biodiesel, e o melaço de soja, co-produto da produção da proteína de soja. Visando contribuir acerca da degradação microbiana destes resíduos, esse trabalho analisou a produção de metano de dois lodos anaeróbios distintos, advindos de reatores UASB (Upflow Anaerobic Sludge Blanket) empregados no tratamento de rejeitos de abatedouro de aves (1) e de Estação de Tratamento de Esgoto (ETE) (2), operados em batelada. Tendo o glicerol ou o melaço de soja na concentração de $10 \mathrm{~g} / \mathrm{L}$ como única fonte de substrato, o resultado dos ensaios permitiu concluir que há viabilidade para a sua degradação por biomassa anaeróbia, oferecendo, assim, uma destinação sustentável para esses resíduos. Os valores máximos da taxa de produção de metano foram de $17,6 \mathrm{mLCH}_{4} / \mathrm{h}$ para o inóculo de reator empregado no tratamento esgoto sanitário e utilizando glicerol como substrato e $44,6 \mathrm{mLCH}_{4} / \mathrm{h}$ para o inóculo de reator que trata resíduos de avicultura com melaço de soja como substrato.
\end{abstract}

\section{INTRODUÇÃO}

Alternativas energéticas renováveis, seguras, sustentáveis e ambientalmente mais corretas que combustíveis fósseis, principais responsáveis pela emissão de gases do efeito estufa, têm sido estudadas, como os biocombustíveis bioetanol, biodiesel e biogás (Viana, 2011).

O principal subproduto da produção de biodiesel é o glicerol que pode ser gerado na proporção de cerca de $10 \mathrm{~kg}$ para cada $100 \mathrm{~kg}$ de biodiesel produzido. Além disso, seu elevado teor de impurezas encarece o processamento industrial, pois sua composição e características dependem do óleo usado para a produção de biodiesel (Viana, 2011; Hutňan et al., 2013). 
O glicerol oriundo da produção de biodiesel é constituído por uma mistura de óleos, ácidos graxos de cadeia longa, metanol, sais e outras substâncias que, se dispostas no meio ambiente sem tratamento adequado, são responsáveis por causar problemas de intoxicação, formação de espumas, mau cheiro e variações nas características de ecossistemas. Com isso, para manter a sustentabilidade econômica e ambiental da produção de biodiesel, é necessário o uso alternativo do glicerol residual (Viana, 2011). Uma possível aplicação é utilizar o glicerol residual na geração de metano por processos biológicos.

A soja é uma cultura cujos produtos são utilizados nas indústrias agroquímicas e de alimentos (Da silva et al., 2012). No Brasil, essa cultura foi a única a ter um crescimento expressivo na sua área cultivada ao longo das três últimas décadas. A Companhia Nacional de Abastecimento (CONAB) estimou uma produção de 96,2 milhões de toneladas na safra de 2014/15.

O melaço de soja é um subproduto proveniente da produção de proteína concentrada de soja que pode ser utilizado na nutrição animal (Siqueira et al., 2008). O processo consiste em uma extração hidrossolúvel (na presença de etanol e água) dos carboidratos a partir do farelo de soja (48\% de proteína). Na corrente alcoólica extrai-se o farelo concentrado e, na outra corrente, o líquido remanescente é chamado de melaço de soja (Letti et al., 2012). Esse material residual é rico em açúcares como: frutose, glicose, sacarose e rafinose. Além do uso para alimentação animal, o melaço é uma fonte adequada para a produção de etanol de soja, pela presença de açúcares fermentescíveis, e também é empregado para queima direta em fornos ou caldeiras. Uma alternativa a esta última seria sua utilização como substrato para produção de metano (biocombustível) via processo biológico anaeróbio. O metano produzido poderia ser empregado na cogeração de energia elétrica para a unidade fabril.

O teste de Atividade Metanogênica Específica (AME) pode ser usado para avaliar o potencial máximo da biomassa contida em um reator anaeróbio em produzir metano e é um importante parâmetro para se quantificar a eficiência da população metanogênica presente, constituindo uma ferramenta de controle operacional (Aquino, et al., 2007). Para que a máxima atividade metanogênica do lodo seja alcançada, é necessária condição específica de anaerobiose, $\mathrm{pH}$, temperatura e concentração de substrato.

Neste trabalho, foram estudados dois substratos distintos que são resíduos em processos de produção de biodiesel, o glicerol, e produção de proteína concentrada de soja, o melaço de soja. Assim, o objetivo foi comparar a atividade metanogênica de dois inóculos anaeróbios (lodos) em concentrações de $10 \mathrm{~g} / \mathrm{L}$ de glicerol e de melaço, separadamente, e sua viabilidade da degradação biológica e consequente produção de biogás pelos inóculos testados.

\section{MATERIAIS E MÉTODOS}

\subsection{Substratos e Inóculos}

O glicerol utilizado foi proveniente de planta piloto de obtenção de biodiesel localizada no IBIOTEC - Instituto de Biotecnologia do Centro Universitário de Araraquara (Uniara) a partir de óleo de cozinha usado. O melaço de soja foi proveniente da empresa de sementes Selecta S.A., unidade fabril que realiza o processamento da soja, extraindo farelo, 
óleo refinado, degomado e concentrados de soja com diferentes teores proteicos, sendo este último produto a origem do melaço. Os inóculos testados eram lodos granulares provenientes de reatores anaeróbios de fluxo ascendente e manta de lodo (UASB - Upflow Anaerobic Sludge Blanket) empregados no tratamento de rejeitos de abatedouro de aves (1) e em Estação de Tratamento de Esgoto (ETE) (2).

\subsection{Reatores Biológicos}

Nos ensaios com glicerol, reatores anaeróbios em duplicata (Frascos de Duran de $500 \mathrm{~mL}$ ) foram operados em batelada sendo o volume reacional total de $250 \mathrm{~mL}$ e os $250 \mathrm{~mL}$ restantes destinados ao headspace. O volume reacional foi composto por cerca de $250 \mathrm{~mL}$ de lodo anaeróbio e 2,5 g de glicerol de modo a atingir uma concentração inicial de $10 \mathrm{~g} / \mathrm{L}$ de glicerol. Os reatores foram mantidos a $30^{\circ} \mathrm{C}$, em repouso por $110 \mathrm{~h}$. Assim, foram estudados reatores com os inóculos (1) e (2), separadamente.

Nos ensaios com melaço, foram utilizados reatores anaeróbios em duplicata (Frascos de Duran de $500 \mathrm{~mL}$ ), sendo o volume reacional total de $400 \mathrm{~mL}$ e $100 \mathrm{~mL}$ destinados ao headspace. Neste caso, o volume reacional foi composto por $50 \%$ de lodo anaeróbio e $50 \%$ de solução aquosa de melaço de soja de modo a atingir uma concentração de $10 \mathrm{~g} / \mathrm{L}$ de melaço de soja. Os inóculos (1) e (2) foram previamente drenados para remoção de água (sedimentação por 3h). Utilizou-se uma maior quantidade de biomassa, neste caso, pois o melaço de soja poderia ser tóxico para os microrganismos quando em grande concentração.

\subsection{Produção de Biogás}

A geração de metano foi quantificada por deslocamento de volume de liquido (água) em um sistema acoplado aos Frascos de Duran composto ainda por frasco lavador, mangueiras e solução de $\mathrm{NaOH}$ 15\% (Aquino, et al., 2007, Nghiem, et al., 2014), conforme esquema apresentado na Figura 1.

Figura 1 - Esquema para medida de produção de metano por deslocamento de volume de líquido.

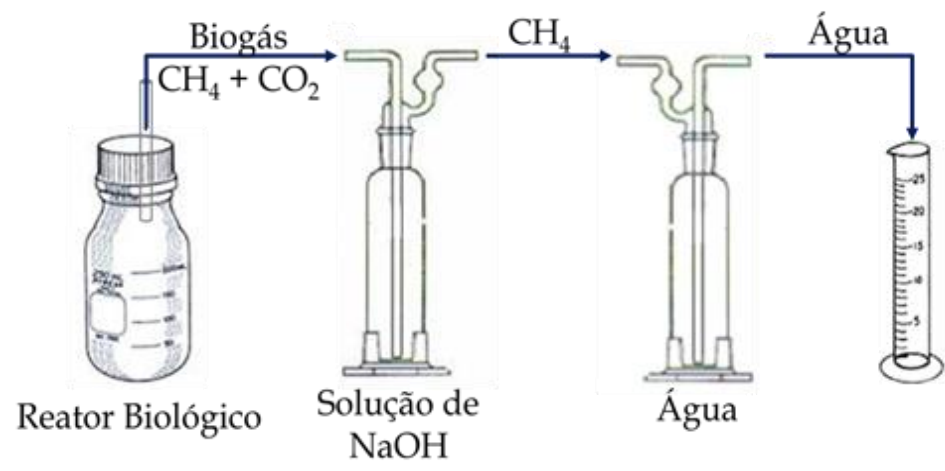

\section{RESULTADOS E DISCUSSÃO}

Para as condições avaliadas observou-se que a concentração de $10 \mathrm{~g} / \mathrm{L}$ de glicerol e de melaço não foi tóxica para o consórcio microbiano, pois ambos os lodos foram capazes de gerar metano (Figura 2 e Figura 3). 
Figura 2 - Volume de metano acumulado ao longo do tempo para os reatores inoculados com lodo de Estação de Tratamento de Esgoto

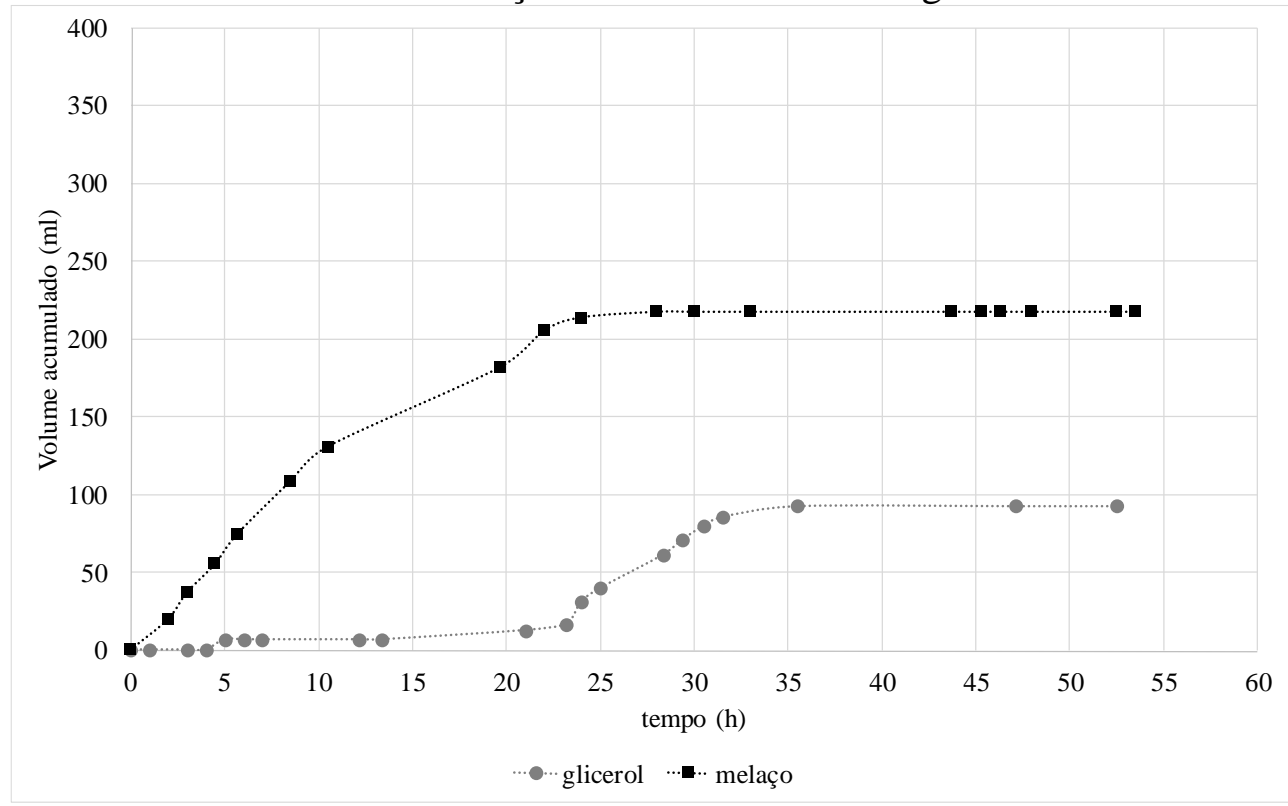

Figura 3 - Volume de metano acumulado ao longo do tempo para os reatores inoculados com lodo de Estação de Tratamento de resíduo de abatedouro de aves

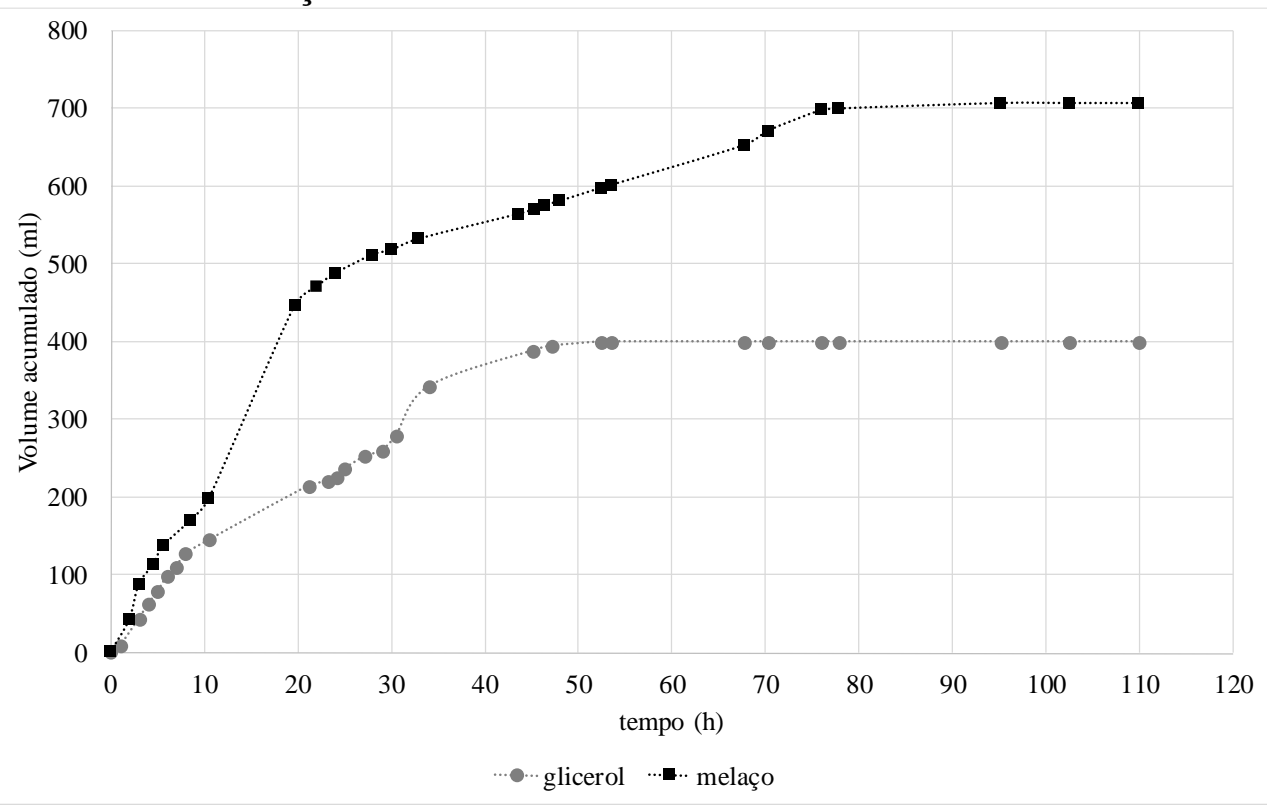

Uma vez que as condições operacionais dos reatores se mantiveram constantes para um mesmo substrato, pode-se observar, analisando as Figuras 2 e 3, que o lodo de resíduos de abatedouro de aves (avícola) apresentou capacidade mais elevada de produção de metano com ambos os substratos, assim como o sucesso na degradação de tóxicos por processos anaeróbios (Lázaro, et al., 2014) e em ensaios de atividade metanogênica (Vich, 2006). 
Assim, a viabilidade de tratamento anaeróbio dos resíduos testados pôde ser comprovada pelo ensaio de AME para ambos os inóculos. A Tabela 1 apresenta os valores máximos de produção de metano bem como sua taxa máxima para cada ensaio.

Tabela 1 - Valores de produção de metano para ensaios de AME com glicerol e melaço de soja como substrato

\begin{tabular}{cccc}
\hline Inóculo & Substrato & $\begin{array}{c}\text { Taxa máxima de produção } \\
\text { de metano }(\mathbf{m L} / \mathbf{h})\end{array}$ & $\begin{array}{c}\text { Produção máxima de } \\
\text { metano }(\mathbf{m L})\end{array}$ \\
\hline ETE & Glicerol & 17,6 & 92,8 \\
ETE & Melaço & 17,0 & 217,2 \\
Avícola & Glicerol & 19,0 & 399,6 \\
Avícola & Melaço & 44,6 & 706,5 \\
\hline
\end{tabular}

Apesar dos ensaios com lodo da Estação de Tratamento de Esgoto (ETE) apresentarem valores próximos de taxa máxima de produção de metano, a diferença nos valores de produção máxima pode ser justificada pela maior quantidade de inóculo presente no ensaio com melaço como substrato, uma vez que o lodo foi adensado antes de sua utilização. A mesma justificativa se aplica na comparação entre os valores de taxa e produção máxima de metano para os ensaios com lodo de abatedouro de aves.

\section{CONCLUSÃO}

Ambos os lodos foram capazes de produzir metano utilizando ambos os substratos, tanto o melaço de soja quanto o glicerol. O inóculo do abatedouro de aves seria o escolhido para aplicação no tratamento de ambos para produção de metano, sendo que, o substrato com maior conversão foi o melaço de soja. A cogeração de energia pelo uso do metano, nesses ensaios específicos é promissora, o que evitaria a queima direta desse biogás, propiciando uma destinação ambientalmente correta e sustentável.

\section{AGRADECIMENTOS}

Os autores agradecem à Estação de Tratamento de Esgoto Monjolinho (São Carlos SP) e Avícola Dacar Ltda. pelo fornecimento dos inóculos, IBIOTEC (Uniara) pelo fornecimento do glicerol e ao CEMPECQ (Centro de Monitoramento e Pesquisa da Qualidade em Combustíveis, Biocombustíveis, Petróleo e derivados) pelo apoio financeiro na aquisição dos equipamentos laboratoriais.

\section{REFERÊNCIAS}

AQUINO, S. F.; CHERNICHARO, C. A. D. L.; FORESTI, E.; SANTOS, M. L. F.; MONTEGGIA, L. O. Metodologias para determinação da atividade metanogênica específica (AME) em lodos anaeróbios. Engenharia Sanitária e Ambiental, v. 12, n. 2, p. 192-201, 2007.

CONAB - COMPANHIA NACIONAL DE ABASTECIMENTO. Soja. Safra 2014/15. Oitavo levantamento, Maio de 2016. Disponível em <http://www.conab.gov.br> Acesso em: 07 jun 2016. 
DA SILVA, F. B.; ROMÃO, B. B.; CARDOSO, V. L.; FILHO, U. C.; RIBEIRO, E. J. Production of etanol from enzymatically hydrolyzed soybean molasses. Biochemical Engineering Journal, 69, 61-68, 2012.

HUTŇAN, M.; KOLESÁROVÁ, N.; BODÍK, I.; CZÖLDEROVÁ, M.; Long-term monodigestion of crude glycerol in a UASB reactor. Bioresource Technology, v. 130, p. 88-96, 2013.

LAZARO, C.Z., PERNA, V., ETCHEBEHERE, C., VARESCHE, M.B.A. Sugarcane vinasse as substrate for fermentative hydrogen production: The effects of temperature and substrate concentration. International Journal of Hydrogen Energy, 39, 6407-6418, 2014.

LETTI, L. A. J.; KARP, S. G.; WOICIECHOWSKI, A. L.; SOCCOL, C. R. Ethanol production from soybean molasses by Zymomonas mobilis. Biomass \& Bioenergy, 44, 80-86, 2012.

NGHIEM, L. D.; NGUYEN, T. T.; MANASSA, P.; FITZGERALD, S. K.; DAWSON, M.; VIERBOOM, S. Co-digestion of sewage sludge and crude glycerol for on-demand biogas production. International Biodeterioration \& Biodegradation, 95, 160-166, 2014.

SIQUEIRA, P. F.; KARP, S. G.; CARVALHO, J. C.; STURM, W.; RODRÍGUEZ-LEÓN; J. A.; THOLOZAN, J. L.; SINGHANIA, R. R.; PANDEY, A.; SOCCOL, C. R. Production of bio-ethanol from soybean molasses by Saccharomyces cerevisiae at laboratory, pilot and industrial scales. Bioresource Technology, 99, 8156-8163, 2008.

VIANA, M. B. Produção de biogás a partir de glicerol oriundo de biodiesel. 2011. 113f. Dissertação (Mestrado) - Escola de Engenharia de São Carlos, Universidade de São Paulo, São Carlos, 2011.

VICH, D. V. Atividade metanogênica e a comunidade microbiana envolvidas na degradação de metilamina. Dissertação (mestrado) - Escola de Engenharia de São Carlos, Universidade de São Paulo, São Carlos, 2006. 